\title{
Living in-between: The Uses of Marginality in Sociological Theory*
}

\author{
Svetlana Bankovskaya \\ Professor of Sociology, National Research University Higher School of Economics \\ Address: Myasnitskaya Str., 20, Moscow, Russian Federation 101000 \\ E-mail: sbankovskaya@gmail.com
}

\begin{abstract}
It may seem that the concept of marginality has already been thoroughly studied and sometimes even considered as a useless and obsolete theoretical notion. However, in this article I develop the notion in a novel way with regard to recent theoretical debates on the social implications of shifting borderlines in the contemporary world. The notion of "marginal man" introduced by Robert Park is central for my approach since it embodies the "spatial-social" interaction. I construct and use the nexus of space, time and movement to account for the analytical capacities of this concept. The article covers mainly the spatial aspects of marginality and its connotations. I outline two main approaches to the ideal type of the "marginal man" in the paper: 1) the spatial-functional approach (traced back to Simmel's notion of Stranger), which focuses on the essential functions of Stranger for a group border, and 2) "formal"making approach to multiple borders (and particularly shifting ones) that shape "marginal's" identification as placed in-between borders and challenge the orderliness of bordered space. The central task of the marginality research is not to classify different "strangers" and "marginals", or to describe their conditions, self-identities, and psychological controversies, but to depict social processes responsible for "marginalization", exclusion, and enabling liminal positions. In this article I argue that the analytical vista of the "marginality" concept can be extended beyond the individual/personal framework and include social institutions (in the example of citizenship).
\end{abstract}

Keywords: space, border, frontier, marginality, marginal man, stranger, movement

There are some concepts in sociological theory that once appeared in the analysis of social phenomena and specific circumstances, and then became irrelevant to current theoretical discourse with changed circumstances. But under certain social changes, these concepts are popular again, and relevant for theory-oriented research. An example of this is the concept of marginality, re-emerging in the wake of American emigration in order explore a new social type, that of the marginal man, and has undergone many reverberations and inversions of meaning. Given its original sociological connotations, the concept of the marginal man is useful, and even indispensable, for the analysis of post-Soviet and current social realities.

The initial difficulty for the research emerged with the social change which used to be called "post-soviet" or "post-imperial." The development of a new social reality produced new social spaces (new states, new borderlines, new "social closures" and new ag-

() Svetlana P. Bankovskaya, 2014

(c) Centre for Fundamental Sociology, 2014

* The results of the project "Emergent vs Imposed Order of Social Life: The Modes of Interaction and Transformations", carried out within the framework of the Basic Research Program at the National Research University Higher School of Economics (HSE) in 2014, are presented in this work. 
gregations; in a word-the "post-Soviet space", entering into the different kind of social analyses), as well as another social time (new regularities, revision of historical narratives, new points of countdown, etc.). These processes inevitably generated (or made evident) a particular social type known as the "marginal man."

The popular preconceptions of "marginals" could be attributed to approximately twenty-five million people in the post-soviet space as they found themselves outside their "historical motherland" within a fortnight. This manifold varies from overt hostility and scorn (when "marginal" means "declassified person", "lumpen", "criminal", "rootless", "vagrant", etc.), to the neutral, formal, or even sympathetic attitude ("migrants", "non-citizens", "double citizens", "refugees", "compatriots abroad”, etc.). The post-soviet marginals could be viewed as exemplifying the universal modern social type of "marginal", determined and formed by the global processes of the framework of experience unification while creating new forms of fragmentation and dispersal. In other words, the definition of the social type of "marginal" was actualized via the modern processes of difference, exclusion and marginalization. ${ }^{1}$

Thus, the conceptual premise of the main research objective formulation consists of the suggestion that "marginal" is a universal social type. Methodologically, this inferred presupposition that "marginality" provides a new "ideal type" for modern social reality analysis, and is made along space/time dimensions.

The main objective of the research on marginality is to develop a conceptual framework of reference for the sociological analysis of marginality as a specific post-imperial social type, process, and social relationship. With regard to this objective, two special tasks could be formulated - to establish contingency of this term with the basic sociological concepts that are generally used to understand the idea of marginality, and to work out a theoretical operationalization of the "marginality" in the context of processes of the destabilized society such as desocialisation and re-socialisation, social/cultural/ political exclusion, hybridization, and diffusion.

As stated, the central question of the marginality research is not to classify different "strangers" and "marginals", or to describe their condition and self-identities, and psychological controversies, but to depict social processes responsible for "marginalization", exclusion, and liminal positions. The identification of such processes generating "marginal" type provides an opportunity to find out a sociological account of the marginal condition as opposed to psychological one. Identifying the principal differences between sociological and psychological approaches to the concept of marginality is one of the significant points of the research on marginality. The central argument of these differences is as follows: the psychological approach, as presented in numerous works on "marginals", "vagabonds", “exiles", "pilgrims", "strangers", etc., focuses on the description of the marginal's feelings, sentiments, consciousness, self-consciousness, memories, and perceptions, while the sociological approach is interested in the marginal's functions in relation to the group, or his/her specific practices developed while being in between the cut-

1. Discussion on these processes see in Giddens, 1991: 5-6. 
lines of different social institutions, or in the forms of the marginal's activity reciprocally producing the processes of institutional marginalization. The further elaboration of the sociological approach to the definition of "marginality" demands a revision, first of all, of the "classical" social theory resources in regard of the new marginalities. The concepts of "the stranger", "the other" and "the marginal man" represented this pull of resources.

The main sources of concepts and ideas relative and useful for the analysis of marginality were the texts of classical sociology. These classical texts could be selected and singled out according to the main categories constituting the concept of marginality: space, time, and movement/mobilities (as well as related categories of norm, and ambivalence). These tentative dimensions of marginality are specified and transformed into the conceptual framework of marginality through the works of G. Simmel on "Stranger" $(1989,1992)$, and through his sociology of space. The dimension of space was concretized by Simmelian terms of "the unity of closeness and remoteness", "host/stranger relationship", and the "stranger's freedom and objectivity." It will be sufficient here to note the research and debate on the Simmelian Stranger and Otherness which resulted, according to Donald Levine, in the classification of different "Stranger" status-types: Guest, Sojourner, Newcomer, Intruder, Inner Enemy, Marginal Man (Levine, 1977). The main criterion for this classification is the Simmelian notion of Stranger as the "co-presence of closeness and remoteness"; all the types/statuses of Stranger classification come from the underlying relationship of Host-Stranger and its emotional character (the degree of compulsive friendliness or hostility); the process of such a relationship is associated with assimilation and its core variable of Estrangement. Any classification is vulnerable to criticism, including this one, if one pursues a classification to fit specific post-imperial conditions. The questions arising from the classification concerns not only the "characteristic properties of each of these types of stranger relationship" (Levine, 1977: 23), or factors determining person's entrance into one or another of these type relations, or person's moving from one type to another; our major interest is the very process by which persons find themselves to become marginals (strangers) in the group, and why this process of marginalization becomes independent of the person's will to stay or leave the group.

Another classical peace of text having the direct influence on the marginality issue is one of A. Schutz on "Stranger" and "Homecomer" (1945). Here time dimension acquired the shape through the concepts of regularity, continuity, routinization, recurrence, simultaneity and others. Significant for the marginality research objectives are also works of G. H. Mead on The Philosophy of the Present (1932); of E. Durkheim on anomie and "moral community" (1906) (for the norm dimension and the modes of "normalization"), but primarily - of R. Park on "marginal man", migration, human ecology and the cycle of "competition/conflict/accommodation and assimilation" (for the movement and ambivalence dimensions).

The most evident definition of the "marginal man" by R. Park comes from the term of the "margin"/"border", and, thus, makes the issue of marginality to be, first of all, the

2. See Park, 1928, 1961, 1967. 
subject of the sociology of space. Although the Park's version of Sociology of Space (Human Ecology) makes its reference to the Simmelian Sociology of Space (particularly to the notion of the Stranger - Der Fremde), it is significantly modified in its epistemological issues. The modification comes, first of all, from the different account of the "border"/"margin" - it is no more defined in the predominately cognitivistic manner, like: "The boundary is not a spatial fact with sociological consequences, but a sociological fact that forms itself spatially" (Simmel, 1997: 143), as the objectification of the human attitude towards the "piece of space", making the sense of group identification. Thus, the account of the Stranger and his relationship to the boundary of the group is essentially functional - the Stranger, by crossing the borders of the group deliberately - unlike group members - makes the group to get aware of what it is not like, he is a pure function of the group identification process. Park comes to his notion of the "marginal man" not only through the reflections on the ideal type of the Stranger and the social-functional meaning of the border, but, first of all, as the theoretical outcome of his empirical studies of the migration process in America. In this theoretical framework the group and the marginal exchange their functions - multiple group boundaries become the source for the marginal's identity, they are embodied in the marginal's personality, crossing the boundary is not just getting close or remote to the group, but to overcome the physical space, to make the interaction with the space. This was a different from Simmelian Sociology of Space, treating space not only as becoming a social fact via human action and experience, but forming and producing social facts. Space and its physical features impact the social institutions and human behavior. The Space is not just the container of the Social, enabling to exercise the human capacity to differentiation, streamline and meaningful ordering, but the primordial state of the Social, its starting point of motion. ${ }^{3}$

Thus, we can talk about another principal distinction between the two main approaches to the analysis of the marginality in sociological theory. One of the approaches could be called "functional": it could be said to regard and define a marginal from the group's point of view. It focuses on the marginal's relation to the group (community, society) and takes "identity" identification with the group) and "participation" (or even loosely comprehensible notion of the norm of participation in group activities) concepts as a frame of reference for this relation. "Identity" and "participation" facilitate the general classification of the functional definitions of "marginality": in the utter case of the definition of marginality "identity-making" could be regarded as participation; this approach to the study of marginality is sooner "actionist" one and corresponds to the subject matter for the study of marginality. It can be complemented by and compared to the study of marginals functions or uses in social and cultural relationship and to the study of the form of marginality under the processes of desocialization and resocialization. Considering the actionist interpretation of marginality (where the core operational concept is participa-

3. As Frederic Turner (certainly known to R.Park) wrote in his notorious work on The Significance of the Frontier in the American History: ". . . the frontier is productive of individualism. Complex society is precipitated by the wilderness into a kind of primitive organization based on the family. The tendency is anti-social. It produces antipathy to control, and particularly to any direct control" (Turner, 1921: 42). 
tion) one cannot but notice that marginality is usually defined as a lack of participation in social institutions (in economics, in political decision making, in symbolic resources' distribution, etc.), as a deprivation and exclusion from the social structures (Germani, 1980). Such point of view provides functionally "negative" aspect of marginality definition. But if the deviation from the participation norm to the opposite extreme-surplus of participation-is suggested, then marginal is located between the different kinds of social borders that shape social relationships and cement social order. This is that positive aspect of marginality definition which has been already stressed by R. Park and which describe the position of the marginal as in-between the worlds, cultures, social orders, not identifying completely with either. This position of in-betweenness facilitates the move towards the "formal" sociological approach to marginality which will be introduced below.

But first, some remarks on the functional definition. Both aspects of the definitionpositive and negative-entail functional meaning: a marginal has a universal social distance enabling him to perform as an observer and providing him with the criterion for observation (the norms of social/cultural/political orders "beyond the border" may serve as such a criterion). It gives an opportunity for the instrumental interpretation of the stranger; Richard Rorty quite frankly suggests this pragmatist "inevitable and unobjectionable ethnocentrism” for the Western culture (Rorty, 1992).

Thus one of the main marginal's functions is to contribute to the process of social self-reflection and society's self identification giving a chance to indicate what society is not alike.

Another functional advantage of marginality consists in that it makes possible to explain social change not necessarily as a result of the systemic crisis, but as a permanent condition of the "complicated strategic situation", of the "interaction among the unequal and mobile social relations" (Foucault, 1984). It helps to escape the necessity to admit the condition of the permanent systemic crisis. Here the change infers no necessarily a conflict, but rather a paradox: the resolution of such a situation requires also paradoxical strategy that does not exclude completely the alternatives for the specific chosen solution, but makes possible to preserve and reproduce them. The condition of marginality (and the presence of marginals), therefore, not only generates an ambiguity/abeyance/ contradiction of the social positions (what makes the problem of social control particularly acute), but also provides with the set of alternatives for the resolution of complex situation.

In other words, the point is that the marginality is an intrinsic feature of the evolutionary development, when there is not any linear, deterministic relation between the certain event (war, revolution, etc.) and the social mutation; the change takes a range of hardly detachable and inaccessible for direct observation stages. Marginals and strangers constitute the material cumulating and transmitting these shades of cultural and social change.

The negative-dysfunctional-aspect of marginality, particularly salient on the institutional level of the social order, clears up during the institutional, systemic crises, when marginals become a result of such a crisis, institutionally surplus material, costs 
for the social change. They actualize the necessity of social control and set the problem of creating new institutional positions for the institutionally ambivalent, abeyant groups (Mizruchi, 1983).

As a distinct from the "functional" approach there could be outlined another also sociological way of "marginality" account based not on the marginal's relation to the group (and thus centered on the marginal's functions and uses for the group), but rather on its relation to many groups (two at least), on its state of in-betweenness and cultural conflict. This approach strives to formalize the condition of marginality in the space/ time/movement dimensions and to depict marginal's position and modes of activity not in functional relation to one group (or subsequently, to one and then to another), but regarding his activity, per se, as located in the definite point of the multi-group environment and effected by the surrounding boundaries and forms. This approach will be referred to as "formal" one. It also, as it was mentioned above, starts from the classical sociology of space and time and, first of all from the Park's concept of "the marginal man" as well as of his vision of the sociology of space ("human ecology") and of the social ontology in general (the cycle of orders "competition-conflict-accommodation-assymilation").

The correlation of the concepts "frontier", "institutional border", "social conflict as a form of social border", "spatial dimension of marginality" is a special point of reference. By the definition marginals and the very process of marginalization presuppose the notion of boundary, edge, limit. Marginals' static uncertainty acquires also dynamics when the established institutional border lines and clear-cuts start to shift and to transform under the social change and become "frontiers"; thus, marginals perform as the main agents of these frontier lines. As to the study of the form of marginality process, it depends on the interpretation of the very notion of "margin" as clear-cut, division, edge, limit, frame, periphery, or frontier.

Time dimension of the marginality is revealed through the concepts of "Homecomer", the presence/absence dialectics in marginal position, routinization of the Marginal, regularity of participation, continuity and simultaneity in the group's "cultural pattern" production and reproduction. "The beginning" of the group was paid a special attention since the revision and rewriting the history or biography of the group is the most effective means of marginalization. In this case the marginal is portrayed as Latecomer, those, "who was not here at the very beginning."

The category of movement as part of the frame of reference for the formal marginality analysis is the less elaborated part of the studies on marginality. Specific forms of mobilities of the marginals (such as oscillations, fluctuations) are of interest here. The further logic of the research on developing marginalities demand to analyze marginal units fixed in space/time dimensions in their change perspective, that is in movement. This will indispensably become the next focus of marginality investigations.

So, the question point was how at all persons are moved to marginal positions, or how they are made to be marginals, or what compels them to perform as marginals.

Keeping in mind these theoretical framework questions Marginality is to be presented through the terms of its Space dimension which covered the following topics: Distinction, 
Distance, Ordering, Border, Frontier, Marginal as a frontiersman, Environment, Center/ periphery, Global marginal. The subsequent part of the Marginality study is evidently centered on the Time dimension of marginality and the topics here are: The Presence/ Absence dialectics in marginal position, Routinization of the Marginal, Regularity, continuity and simultaneity in the group's "cultural pattern" production and reproduction, "The beginning" of the group and marginal as Latecomer, Eternal Marginal. Another part of the study deals with the functional meaning of Marginality and puts forward questions on: Participation/exclusion, Marginal as an observer, Ambivalence, abeyance and contingency, Marginal as a radical and as a conservative, Astrangement/Assymilation and the problem of Control, The logic of transformation "The Other-The Stranger-The Enemy."

Among the new questions, which infer from this analysis, the crucial one concerns the reflexivity of the marginal man: is the marginal man always aware of his marginality? Whether the very state of marginality develops on the individual (personal) level, as "the conflict of cultures", or it might also proceed on the super-individual (institutional, societal) level independent of the individual intentions and involving individuals (and collectivities as well) into the process of marginalization? If these levels are interconnected, then what are the mechanisms, or patterns, of this alliance?

This issue could be illustrated by the marginal case of the post-soviet/Russian citizenship, which is one of the recent uses of the marginality theory for the analysis of the social institution. The main point is that the post-soviet citizenship is marginalized between the formal (written in the Constitution law on citizenship) norms defining "a citizen" and the actual practices of performing as a citizen. Specific citizen's rights and duties (first of all the right to vote in the elections) can be enjoyed and performed by those who are not formally citizens. Such a situation stems from the old soviet practice to equate "citizens" and "permanent residents" of the country. Permanent residents (after 1992) - by the new post-soviet formal rules-are not automatically entitled to Russian citizenship (they have to pass the procedure of naturalization for that), but in practice they could vote since the electorate are still formed by the permanent residents, not by the "formal" citizens. The peculiarity of the situation is amplified by the fact that neither "a lay voter", nor an official election functionary always realizes the difference between citizenship and permanent residency and can be aware of the constant resident non-citizen's marginal position. Perhaps, the number of such "marginal voters" is insignificant for the elections final results (no one ever measured it), but the very their existence is a remarkable feature of the postsoviet political and civic culture (Bankovskaya, 2006). This case can be very useful for the further analysis of the relationship between "social/political" and "spatial" dimensions in the process of marginalization.

Turning to the conditions of the post-soviet marginalization it is worth to mention peculiarities of this process concerning the relation between "borders" and "marginal." Usually marginals, strangers, newcomers, etc. are seen as trying to transcend the border, to erase it, to make it transparent and flexible; they try to combine the attributes of two (or more) form-units (Herrick, 1977; Tirykian, 1973). 
The post-imperial case here deals with the process of marginalization which take place in the conditions of emerging borders, multiplying boundaries (spatial, institutional, symbolic); the initial unit falls apart, the diffuse, social and cultural space become an environment, marginalia, for the newly formed concentrated clots of social and cultural reality.

Marginal here faces a choice: to join this new form of social organization, to accept a new form of relationship and to identify oneself with it, by the word-to enter inside the bounded entity. The alternative offers to stay beyond the new boundaries, in the former diffuse environment. Sometimes staying in between means to survive on the frontier line, where two new entities are still interacting, conflicting, dividing spatial resources, and still forming the borderlines between them.

So, the marginal in such a position tries rather to escape, to avoid the contact with borders and clear-cut lines, then to combine or erase them. He seems to be in a conflict with the borders and perceives their reality and relativity particularly clear and acute. This type does not seem to be more emancipated and exempt from the control of the custom and tradition (Park, 1967); he rather meets a necessity to confront the growing and multiplying control modes around him; marginal is smashed by the need to defend himself against the attempts to swallow his independent ambiguity and to absorb it into the definitely formed unit. If Simmelian Stranger presupposed both "from every given point in space, and thus the conceptional opposite to fixation at such a point" (Simmel, 1950: 402), then in our case we should sooner speak about the liberation of given point space from the stranger and as opposite-fixation, or keeping him close.

The phase of spatial alteration of the social/cultural forms-expansion or contraction-creates problems (and perspectives) emerging along with the necessity to deal with the new (predominately spatial in its nature) interpretation of post soviet political and social context as an "empire"; the very presence of the "post-soviet space" in the political discourse and practice indicates on the reality of the social entity without the actual borders (since the borders of the Soviet state do not exist), still the meaning of this entity and its contents are real and functional. Thus, marginals could be also portrayed as the essentially "imperial" agents, as agents of the "post-soviet" meaning.

The most complicated theoretical setback becomes the concept of the "social norm" ("anomie"), specifically-"norm of social participation" (and non-participation). It acquires particular meaning when "the new democratic order" is dealt as a result of spatial transformation. Here the problem of marginality bridges the realms of political and social/cultural, since it actualizes a perspective of perversion a Stranger into an Enemy. The process of marginalization, thus being a ferment of the political transformation and re-identification, performs also as a counterbalance to the unification and "massification" of modern democracies.

Thus, the logic of the "marginality" investigation and the methodology of its framework construction consisted in conceptual operationalization of the basic categories of "space", "time" and "movement" to the grid of concepts appropriate for the adequate ac- 
count both of the ideal type of the "marginality" as a special social relation and of particular modes in which it is embodied.

One more principal question concerned the identity of the marginal. It inferred, at least two points. What way the identity of the "marginal" could be defined if not from the point of view of the group? Regarded functionally, from the group positions, marginal is a part of the group's environment, milieu, which is unified, formless and perceived functionally. Reciprocally, from the point of view of the marginal (as to his identity) any definite group is a part of his environment. The variety of distinct, clearly formed up communities, of their borders and the multitude of different kinds of oppositions and distinctions in general constitute the universal "environment" for the marginal. ${ }^{4}$ For the marginal the universal features of the group have the prior meaning; those features which make all the groups more abstract and "imagined", and equally probable to occur in the constellation of his identity. The occurrence of individual in the social circles' crossing is not always a result of individual's own efforts, not always is it even realized by the individual. The identity of the marginal, based on the constellation of the different groups' borders, is distinct from the identity of any other contemporary, also based on the interference and crossing of various social circles, by the fact that marginal, first, uses the resources of the "environment" for self-identification, thus initiating this constellation, or in any rate, realizing its significance for his own identity; and, second, marginal does not fully identify himself with this constellation, always keeping in mind the possibility to change it.

Marginal represents, figuratively speaking, that who formulates his life narrative not by the expressions of the kind "It happened so", but of the kind "I did it so."

Such a reflexivity in relation to self-identity means the more free choice among the equally probable alternatives and the more varied styles of life. The main modern cultural contradiction as to the marginal/stranger could be expressed via the contradiction between the growing abstractness (and inner differentiation) of the collectivity and the diminishing individual opportunities to use this variety of constellations and crossings for self-identification: the choice is too large, but choice criteria are too scarce and they are too abstract. The shadow side of the marginal's freedom and the dramatics of his condition reveals in what Giddens refers to as "existential isolation": this is not as much the isolation of the individuals from each other but rather the separation of individuals from the "moral resources" rendered by the particular group and comprising the criteria for the individual's choice (Giddens, 1991: 9). The core question on the marginal's freedom in the modern cultural environment could be as well formulated as follows: whether marginal's freedom from the group norms means the exemption of the morals from the localism, particular forms and the realization of the universal human values, or it means the "existential isolation" followed by the loss of the person's meaning?

4. The role of the marginal in his relationship with the group could be compared with the role of money in transactions: as money is an embodiment of a pure form in modern economic-and not merely economicexchange, which expels the individuality and concreteness of the situation; the marginal is a form of identity, which expels any particular features of the communities which the marginal is phenomenally bound to. 
Thus, the reflexive constellation of the different collectivities' borders into the identity of the marginal comprises his authenticity, uniqueness and contingency..This infers not only marginal's predisposition to the "erasing of the borders", to their relativization, but also to the special kind of conservatism in relation to the cut-lines. The ambiguity and the state of in-betweenness of the marginal is set by the fact that he, being exempt from the bound to the collectivity which participated in his identity, still remains dependent on their clear-cuts and distinctions, on their mutual oppositions: if their form and concreteness is lost or erased completely, then the marginal's identity definition via the constellation of these forms will also lose its sense, the unique combination of various definite oppositions will be messed. Being aware of the fact that his authenticity depends on the compilation of definite forms marginal contributes to their preserving and cultivation to the extent, to what marginal strives to preserve and cultivate his own authenticity. Definite forms and oppositions are not unified or eliminated in the process of marginalization, but the opportunities to combine them keep in growing; accordingly, multiply also the types of marginals.

\section{References}

Bankovskaya S. (2006) Migraciya, svoboda i grazhdanstvo: paradoksy marginalizacii [Migration, freedom and citizenship: the paradoxes of marginalization]. Polis, no 4, pp. 120-126.

Durkheim E. (1906) La détermination du fait moral. Bulletin de la Sociéte Française de Philosophie, no 6, pp. 113-167.

Foucault M. (1984) Le Souci de soi, Paris: Gallimard.

Germani G. (1980) Marginality, New Brunswick: Transaction Books.

Giddens A. (1991) Modernity and Self-Identity, Cambridge: Polity Press.

Herrick R. (1977) The paradox of marginality. Our Sociological Eye: Personal Essays on Society and Culture (ed. A. B. Shostak), Port Washington: Alfred, pp. 67-79.

Levine D. N. (1977) Simmel at a distance: on the history and systematics of the sociology of the stranger. Sociological Focus, vol. 10, no 1, pp. 15-29.

Mead G. H. (1932) The Philosophy of the Present, Chicago: Open Court Publishing.

Mizruchi E. H. (1983) Regulating Society: Marginality and Social Control in Historical Perspective, Chicago: Chicago University Press.

Park R. E. (1928) Human migration and the marginal man. American Journal of Sociology, vol. 33, no 6, pp. 881-893.

Park R. E. (1961) Introduction. Stonequist E. V. The Marginal Man: A Study in Personality and Culture Conflict, New York: Russell and Russell, pp. xiii-xviii.

Park R. E. (1967) On Social Control and Collective Behavior, Chicago: Phoenix Books.

Rorty R. (1992) Cosmopolitanism without emancipation: a response to Lyotard. Modernity and Identity (eds. S. Lash, J. Friedman), Oxford: Blackwell, pp. 59-71.

Schutz A. (1945) The homecomer. American Journal of Sociology, vol. 50, no 5, pp. 369376. 
Simmel G. (1950) The stranger. The Sociology of Georg Simmel (ed. K. H. Wolff), Glencoe: The Free Press, pp. 420-408.

Simmel G. (1989) Philosophie des Geldes, Frankfurt am Main: Suhrkamp.

Simmel G. (1992) Soziologie: Untersuchungen über die Formen der Vergesellschaftung, Frankfurt am Main: Suhrkamp.

Simmel G. (1997 [1903]) The sociology of space. Simmel on Culture: Selected Writings (eds. D. Frisby, M. Featherstone), London: Sage, pp. 137-170.

Tiryakian E. A. (1973) Perspectives on the stranger. The Rediscovery of Ethnicity (eds. S. TeSelle), New York: Harper and Raw, pp. 45-58.

Turner F. J. (1921) The Frontier in American History, New York: Henry Holt and Company.

\section{Между границ: понятие маргинальности в социологической теории}

\section{Светлана Баньковская}

Кандидат философских наук, ведущий научный сотрудник Центра фундаментальной социологии ИГИТИ НИУ ВШэ

Адрес: ул. Мясницкая, д. 20, Москва, Российская Федерация 101000

E-mail: sbankovskaya@gmail.com

Понятие «маргинальность» может показаться хорошо изученным. Иногда его даже не считают полезным теоретическим инструментом. Однако в данной статье предпринята попытка заново приступить к исследованию данного понятия в связи с социальными последствиями изменения границ в современном мире. Центральным здесь оказывается введенное Робертом Парком понятие «маргинальный человек». «Маргинальный человек» воплощает в себе взаимодействие пространственного и социального. Выявление аналитического потенциала этого понятия может происходить в измерениях пространства, времени и движения. В статье рассматриваются по преимуществу пространственные аспекты маргинальности очерчены два основных подхода к идеальному типу маргинального человека. Пространственно-функциональный подход, восходящий к «Чужаку» Зиммеля фокусируется на определении функций Чужака для границ группы. «Формальный» подход исходит из множественности границ (в особенности из того, что границы меняются и смещаются). С этой точки зрения маргинал есть тот, кто находится между границами и бросает вызов упорядоченности разделенного границами пространства. В статье утверждается, что аналитическая перспектива понятия «маргинальность» может быть расширена. Маргинальным может быть не только человек, но и институты. Главным вопросом исследования маргинальности является не классификация чужаков и маргиналов и не описание условий их жизни, идентичности и психологических сложностей, но описание социальных процессов, вызывающих маргинализацию, исключение, появление лиминальных позиций. В качестве исследовательского кейса в статье использован институт гражданства. Ключевые слова: пространство, время, граница, фронтир, маргинальность, маргинал, чужак, движение 